\title{
pro.posições
}

$e$-ISSN 1980-6248

http://dx.doi.org/10.1590/1980-6248-2016-0070

ARTIGOS

\section{Práticas de desenho e saberes geométricos nos manuais escolares do século XIX ${ }^{1}$}

\section{Drawing practices and geometric knowledge in the Textbooks of the 19th century}

(i) Universidade Federal de São Paulo - Unifesp, Diadema, SP, Brasil. https://orcid.org/0000-00016029-0490, mcelialeme@gmail.com

Resumo: O artigo analisa as diferentes práticas de desenho no processo de escolarização de saberes geométricos presentes nos manuais escolares do século XIX e discute as diferenças entre os manuais traduzidos e a produção brasileira. A pergunta que norteia a análise é: como as práticas de desenho participam do processo de escolarização dos saberes geométricos? Os manuais revelam a presença de duas abordagens distintas para a escolarização de saberes geométricos: o desenho à mão livre e o desenho geométrico, com instrumentos. Apesar de as traduções de manuais estrangeiros propagarem marcas do método intuitivo, em que o desenho à mão livre escolariza os saberes geométricos, tal proposta não prevalece nas produções brasileiras, que se caracterizam pelo desenho geométrico de figuras previamente definidas, de modo que os saberes geométricos sustentam a prática do desenho.

Palavras-chave: práticas de desenho, saberes geométricos, manuais escolares, século XIX

\footnotetext{
${ }^{1}$ Este artigo resultou de pesquisa desenvolvida com auxílio da Fapesp e da Capes/Cofecub.
} 


\section{pro.posıções}

$e$-ISSN 1980-6248

http://dx.doi.org/10.1590/1980-6248-2016-0070

Abstract: The article analyzes the different drawing practices in the educational process of geometric knowledge present in the textbooks of the 19th century and discusses the differences between the translated books and the Brazilian production. The question guiding the analysis is: How do drawing practices take part in the education process of geometric knowledge? The textbooks reveal the presence of two distinct approaches to the education of geometric knowledge: the freehand drawing and the geometric drawing with instruments. Despite the translations of foreign books propagating elements of the intuitive method, in which freeband drawing formalizes geometric knowledge, this proposal does not prevail in Brazilian productions, characterized by geometric drawings of predefined figures, so that the geometrical knowledge supports the drawing practice.

Keywords: drawing practices, geometric knowledge, textbooks, 19th century

\section{Considerações iniciais}

O presente artigo analisa as diferentes práticas de desenho no processo de escolarização dos saberes elementares geométricos ${ }^{2}$ para o curso primário no decorrer do século XIX. A investigação toma como fonte manuais escolares ${ }^{3}$ traduzidos, adaptados e produzidos no Brasil Império e nos primeiros anos da República.

Pode-se dizer que se trata de um período de nascimento e constituição do ensino primário brasileiro, momento de pouquíssima produção de livros destinados ao ensino, em especial, ao ensino de primeiras letras. É a partir da segunda metade do século XIX que se identificam as primeiras obras para o ensino de desenho e de geometria de autoria nacional direcionadas ao ensino primário.

Desde já, é importante ressaltar a marca da circulação de ideias francesas na área da educação brasileira durante o século XIX:

A necessidade de um embasamento científico para o desenvolvimento da educação faz com que os intelectuais brasileiros se apropriem das idéias de representantes da intelectualidade francesa

\footnotetext{
2 Opta-se por usar o termo "saberes elementares geométricos", entendendo-o como o conjunto de conceitos, definições, temas, propriedades e práticas pedagógicas, relacionados à geometria, que estejam presentes na cultura escolar primária.

${ }^{3}$ De acordo com Choppin (2009), "hoje, ainda, os termos aos quais recorrem as diversas línguas para designar o conceito de livro escolar são múltiplos, e sua acepção não é precisa, nem estável” (p.19). Assim, no presente estudo, denominam-se manuais escolares todos os livros que trazem orientações didáticas aos professores ou monitores (no caso do período do ensino mútuo), atividades propostas para serem desenvolvidas pelos alunos, e que indiquem ou façam referência ao seu uso nas escolas primárias.
} 


\section{pro.posıções}

$e$-ISSN 1980-6248

http://dx.doi.org/10.1590/1980-6248-2016-0070

para dar voz e força às idéias que consideram relevantes e significativas para serem implementadas. (Bastos, 2000, p. 81)

As traduções e as adaptações de manuais escolares estrangeiros durante o século XIX no Brasil inserem-se no rol de experiências estrangeiras que participam significativamente do processo de construção de um modelo de ensino primário brasileiro. De outra parte, a análise da circulação internacional de propostas para o ensino de desenho e saberes geométricos através de manuais escolares evidencia a singularidade das apropriações brasileiras. E aqui cabe considerar os ditames do historiador Chartier (2009):

a força dos modelos culturais dominantes não anula o espaço próprio de sua recepção..., a imposição de disciplinas inéditas, a insinuação de novas submissões, a definição de novas regras de conduta sempre devem ceder ou negociar com as representações arraigadas e as tradições partilhadas. (pp. 46-47)

Como se verifica no decorrer das análises, as primeiras traduções e adaptações de manuais estrangeiros para o ensino de desenho e geometria estabelecem conexões com propostas e modelos franceses para o ensino de desenho e de geometria, sem, contudo, reduzirse a cópia ou reprodução, de modo a:

reconhecer a maneira como os atores sociais dão sentido a suas práticas e a seus enunciados e ... as capacidades inventivas dos indivíduos e das comunidades, as restrições e as convenções que limitam, de maneira mais ou menos clara conforme a posição que ocupam nas relações de dominação, o que lhes é possível pensar, dizer e fazer. (Chartier, 2009, p. 49)

Nesse contexto, selecionaram-se seis manuais para analisar: três livros considerados como tradução e adaptação de obras estrangeiras e três obras de autoria brasileira, que começaram a ser produzidas a partir da segunda metade do século XIX.

Tudo indica que os manuais inventariados constituem referências, parâmetros para a emergência da organização escolar primária republicana - os grupos escolares - iniciada no estado de São Paulo a partir de 1893 e tomada como modelo para os demais estados brasileiros no final do século XIX e início do século XX.

Estudos anteriores com ênfase nas normatizações permitiram inferir que o desenho, como saber escolar, ao ingressar nos programas do curso primário, em meados do século XIX, 


\section{pro.posıções}

$e$-ISSN 1980-6248

http://dx.doi.org/10.1590/1980-6248-2016-0070

impulsionou, estimulou e contribuiu para a permanência e a consolidação dos saberes geométricos no ensino primário.

As perguntas que norteiam a análise sobre os seis manuais são: como as práticas de desenho participam do processo de escolarização dos saberes geométricos? Em outras palavras, o desenho é considerado um método para o ensino dos saberes elementares geométricos ou os saberes elementares geométricos sustentam a prática do desenho?

\section{Práticas de desenho e saberes geométricos nos manuais estrangeiros}

A obra Princípios do desenho linear compreendendo os de geometria pratica, pelo método do ensino mútuo, publicada em 1829, muito provavelmente é a primeira destinada ao ensino de desenho no curso primário. O manual é uma adaptação, feita por A. F. de P. e Iollanda Cavalcanti d'Albuquerque, da obra francesa assinada por Louis-Benjamin Francœur. As Instruções Gerais para o Professor e Decurião ${ }^{4}$ orientam como deve ser o ensino:

Professor, Decurião, e discípulos são considerados no mesmo gráo d'instrucção nesta arte, ou com pouca diferença, e todavia ensinão-se huns aos outros, sem dar preceito algum, e só a força d'imitação. [ênfase adicionada] $\mathrm{O}$ progresso do ensino he antes devido á boa ordem, e zêllo, do que ao saber do mestre (Albuquerque, 1829, pp. 4-5).

Fica explícita a importância de práticas de imitação, visto que nenhuma outra orientação será dada aos alunos: eles devem realizar sucessivos desenhos, até que obtenham a precisão, que é verificada pelo Decurião, empregando os instrumentos em sua avaliação. O ofício do aluno é de praticar a arte de desenhar; desse modo, por meio de desenho de figuras geométricas repetitivas os saberes geométricos são apresentados e compreendidos. A verificação realizada pelo Decurião exige traços firmes e retos: "há tanto merecimento em corrigir hum traço, ou em perceber aonde, e de que maneira elle he defeituoso, como em traçar correctamente" (Albuquerque, 1829, p. 5).

\footnotetext{
4 "Nos métodos de ensino individual e simultâneo, o agente de ensino é o professor. No método mútuo, a responsabilidade é dividida entre o professor e os monitores, visando a uma democratização das funções de ensinar" (Bastos, 1997, p. 117).
} 


\section{pro.posıções}

$e$-ISSN 1980-6248

http://dx.doi.org/10.1590/1980-6248-2016-0070

Para realizar o desenho, é necessária a observação atenta do modelo, a fim de obter uma boa reprodução, e assim, evidenciar-se a prática de medir, feita através do treino do olhar:

Convem, especialmente, que o discípulo se familiarize com as medidas metricas liniares e de capacidade; o olho deve-lhe ser hum regulador tão certo, como se elle servisse de um metro: basta de o habilitar á isso, para que o sentido da vista the seja um guia quasi infallivel (Albuquerque, 1829, p. 6)

Os instrumentos (régua, transferidor, compasso, etc.) são de uso exclusivo dos professores e dos decuriões. Tudo indica que são as práticas de desenhar à mão livre que caracterizam o ensino de saberes geométricos:

Serve-se em Geometria de huma multidão de palavras, taes como diametro, parallela, rectangulo, que tem significações precisas. O Professor deve conhece-las, e nós as explicaremos á medida, que for necessario, ... os outros discípulos não tem dellas necessidade; a forma do modelo e o babito de os imitar basta para fazer dar á estas palavras hum sentido claro, sem que sejão uteis as explicações.... O uso fará mesmo supérfluas outras instrucções [ênfase adicionada]. (Albuquerque, 1829, pp. 6-7)

O ensino de saberes geométricos se traduz pelo hábito de imitar modelos, pela prática de desenhar à mão livre; não se teorizam conceitos geométricos, somente as práticas de um desenho perfeito (manuseio firme, observação atenta e medida precisa com o olhar) respondem às demandas de ensino. Segundo D'Enfert (2007), as atividades do livro de Francœur constituem uma maneira "simplificada" do método de Pestalozzis":

Para Pestalozzi, o conhecimento tem fundamento na percepção sensível da natureza, e, mais particularmente, nas sensações visuais. Mas o conhecimento dos objetos não deve resultar somente das impressões produzidas pelos sentidos. Ele repousa sobre um ABC da intuição ou $\mathrm{ABC}$ da percepção que, para uma "arte da medida" [ênfase no original], leva à observação das formas e a sua comparação com as figuras geométricas elementares, e depois à sua representação através do desenho. Para o autor, o estudo do desenho, e mais particularmente do desenho linear, não é senão a realização dessa aptidão para perceber as relações que se adquire pela observação e identificação do nome e dos objetos. (p. 44)

Assim, pode-se caracterizar a obra de Albuquerque, traduzida e adaptada de Francœur, como uma proposta de ensino de saberes geométricos com marcas do método intuitivo, ou seja,

\footnotetext{
${ }^{5}$ Johann Heinrich Pestalozzi (1746-1827), educador suíço. Suas ideias demarcam a Pedagogia Intuitiva, cuja característica básica é oferecer, na medida do possível, dados sensíveis à percepção e à observação dos alunos (Zanatta, 2012).
} 


\section{pro.posições}

$e$-ISSN 1980-6248

http://dx.doi.org/10.1590/1980-6248-2016-0070

em 1829, em um Brasil recentemente independente, uma das primeiras obras para orientar práticas de ensino de saberes geométricos na escola de primeiras letras do Brasil apresenta proposta de ensino pautada na observação e na reprodução de modelos, na ausência de definições, nas práticas de desenho à mão livre sustentadas pelo treino na habilidade da mão nos traçados e dos olhos para as medidas.

Dificilmente uma proposta como tal seria incorporada à realidade brasileira; de todo modo, é significativa a conexão de intelectuais brasileiros com o estrangeiro, como o deputado Albuquerque, que adaptou e traduziu manual de vanguarda produzido na França dez anos após a publicação no original.

A segunda obra analisada é um manual destinado a todas as matérias, Manual das escolas elementares d'ensino mutuo, publicada em 1854 pelo professor João Alves Portella, que havia sido enviado em missão de estudo ${ }^{6}$ na Escola Normal da capital francesa e que no retorno, em 1842, foi nomeado para a Cadeira de Ensino Mútuo e Simultâneo da Escola Normal da Bahia (D’Esquivel, 2015). A obra original Manuel des écoles élémentaires ou exposé de la méthode de l'enseignement mutuel é de M. Sarazin e foi publicada em 1831. A parte do manual de Portella designada ao ensino de desenho contém somente 7 páginas, de um total de 118. "Do ensino do desenho linear" é o título do capítulo que, no livro original, corresponde ao capítulo VI "Dessin Linéaire". Tanto no original como na tradução, os conteúdos são organizados em 8 classes, de acordo com o Quadro 1:

\footnotetext{
${ }^{6}$ Matasci (2015) analisa as missões de estudo ou missões pedagógicas ao estrangeiro na França e considera-as como elemento central para compreender a circulação dos discursos pedagógicos do século XIX.
} 


\section{pro.posições \\ $e$-ISSN 1980-6248}

Quadro 1 - Organização dos desenhos na obra original e na tradução/adaptação

\begin{tabular}{|c|c|c|c|c|}
\hline \multicolumn{2}{|r|}{ Sarazin $(1831$, p. 46$)$} & \multicolumn{3}{|c|}{ Portella $(1854$, p. 63$)$} \\
\hline $\begin{array}{c}1 .^{\mathrm{a}} \\
\text { classe }\end{array}$ & $\begin{array}{c}\text { Traçado de linhas retas e de } \\
\text { ângulos }\end{array}$ & \multirow{5}{*}{$\begin{array}{l}\text { Desenho } \\
\text { com a mão } \\
\text { levantada }\end{array}$} & $\begin{array}{c}1 .^{\mathrm{a}} \\
\text { classe }\end{array}$ & Traçado e divisão de linhas retas \\
\hline $\begin{array}{c}2 .{ }^{\mathrm{a}} \\
\text { classe }\end{array}$ & Triângulos e quadriláteros & & $\begin{array}{c}2 .{ }^{\mathrm{a}} \\
\text { classe }\end{array}$ & Traçado e divisão de ângulos \\
\hline $\begin{array}{c}3 .^{\mathrm{a}} \\
\text { classe }\end{array}$ & $\begin{array}{c}\text { Polígonos irregulares, } \\
\text { triângulos e polígonos } \\
\text { semelhantes }\end{array}$ & & $\begin{array}{l}3 . .^{\mathrm{a}} \\
\text { classe }\end{array}$ & $\begin{array}{l}\text { Triângulos, quadriláteros, } \\
\text { polígonos irregulares }\end{array}$ \\
\hline $\begin{array}{c}4 .^{\mathrm{a}} \\
\text { classe }\end{array}$ & Pirâmides e prismas & & $\begin{array}{c}4 .^{\mathrm{a}} \\
\text { classe }\end{array}$ & $\begin{array}{c}\text { Linhas curvas, círculo e polígonos } \\
\text { regulares }\end{array}$ \\
\hline $\begin{array}{c}5 .^{\mathrm{a}} \\
\text { classe }\end{array}$ & Círculo e polígonos regulares & & $\begin{array}{c}5 . .^{\mathrm{a}} \\
\text { classe }\end{array}$ & $\begin{array}{c}\text { Pirâmides, prismas, cones, } \\
\text { cilindros, esfera e poliedros } \\
\text { regulares }\end{array}$ \\
\hline $\begin{array}{c}6 .{ }^{\mathrm{a}} \\
\text { classe }\end{array}$ & Cone, cilindro e esfera & \multirow{3}{*}{$\begin{array}{c}\text { Traçado } \\
\text { geométrico }\end{array}$} & $\begin{array}{c}6 .{ }^{\mathrm{a}} \\
\text { classe }\end{array}$ & $\begin{array}{l}\text { Traçado e divisão de linhas retas, } \\
\text { de circunferência e de ângulos }\end{array}$ \\
\hline $\begin{array}{c}7 .^{a} \\
\text { classe }\end{array}$ & Vasos, molduras, etc. & & $\begin{array}{l}7 .^{\mathrm{a}} \\
\text { classe }\end{array}$ & $\begin{array}{c}\text { Triângulos, quadriláteros e } \\
\text { polígonos regulares }\end{array}$ \\
\hline $\begin{array}{c}8^{\mathrm{a}} \\
\text { classe }\end{array}$ & $\begin{array}{l}\text { Elevações, planos, projeções, } \\
\text { desenho de máquinas, etc. }\end{array}$ & & $\begin{array}{c}8 .^{\mathrm{a}} \\
\text { classe }\end{array}$ & $\begin{array}{l}\text { Tangentes, curvas com diversos } \\
\text { centros, secções cônicas e } \\
\text { aplicações diversas de desenho }\end{array}$ \\
\hline
\end{tabular}

Fonte: Sarazin (1831) e Portella (1854)

Ao analisar os desenhos do manual de Sarazin, verifica-se a marcha do ensino proposto, que parte de figuras geométricas planas para as figuras espaciais, finalizando com desenhos de objetos. Entretanto, a tradução de Portella revela uma adaptação da proposta de Sarazin, mantendo a sequência plano para espaço, porém com a divisão estabelecida entre desenho com a mão levantada e desenho geométrico, excluindo os desenhos de objetos e acrescentando a repetição de algumas classes, como se observa na 3 . $^{a}$ e na $7 .^{a}$ classes, que são idênticas.

Não há explicação no manual de Portella sobre a diferença entre desenho com a mão levantada e desenho geométrico; tudo indica que seja a ausência de instrumentos, no primeiro caso, e o uso deles, no segundo. Vale ainda considerar que a expressão francesa dessin à main levée pode ter sido traduzida como "desenho com a mão levantada", porém atualmente utiliza-se a expressão “à mão livre”.

Quanto ao método, a orientação de Portella é que as figuras sejam feitas sem instrumentos. De maneira similar à obra de Albuquerque, os instrumentos ficam com os monitores que fazem a correção dos desenhos: 


\section{pro.posıções}

$e$-ISSN 1980-6248

http://dx.doi.org/10.1590/1980-6248-2016-0070

Quando elles tem para isso recebido ordem, tomão seos pequenos instrumentos, regoa, esquadria e compasso, que precedentemente devem ter sido postos nos logares dos monitores, ao mesmo tempo que os pequenos quadros de desenho, e as folbas de questões [ênfase no original]; e, parando à direita de cada discípulo, corrigem algumas figuras, endireitando uma linha por meio de regoa, dando um angulo recto a abertura conveniente por meio de esquadria, vendo si certo angulo esta bem dividido em partes iguaes por meio do compasso. (Portella, 1854, p. 64)

Há ainda outra recomendação sobre os métodos:

1० methodo. O monitor mostra e nomêa a figura, que se deve traçar; um discípulo a nomêa e executa. Todos os outros discípulos a nomeão [ênfase adicionada]e executão; o monitor a desenha por último.

$2^{\circ}$ methodo. O monitor mostra, sem nomeal-a, a figura, que deve traçar; o discípulo a nomêa e a executa[ênfase adicionada]. O resto como âcima.

$3^{\circ}$ methodo. O discípulo executa a figura, que se lhe dictou, e avalia no todo ou em partes as suas dimensões em decimetros ou em centimetros. O meio-metro do monitor lhe serve para depois verificar se a execução foi exacta. (Portella, 1854, p. 65)

Observa-se, nos dois primeiros métodos propostos por Portella, que as figuras são nomeadas pelo monitor ou pelo discípulo, o que os diferencia da proposta de Albuquerque, em que fica explícita a não necessidade de nomear as figuras. Novamente, trata-se de adaptação de Portella, visto que, na versão de Sarazin (1831), não há indicação de nomear as figuras, a orientação é: "Para que os alunos conheçam a definição das figuras geométricas que eles desenharam, os professores deverão redigir, colocar no quadro e ler para os alunos avançados" (p. 49, tradução nossa).

Assim sendo, pode-se dizer que o manual de Portella propõe um ensino de desenho de figuras geométricas sustentado pelas práticas de desenhar à mão livre, sem instrumentos. A prática do desenho, do medir com os olhos, de traçados firmes para reproduzir continua presente, porém há indícios de que o traçado geométrico sugira práticas de desenho com instrumentos e a orientação para nomear as figuras antes de seu traçado completo e perfeito, o que coloca em discussão princípios do método intuitivo.

Finalmente, o último manual estrangeiro analisado é o manual Primeiras lições de coisas. Manual de ensino elementar para uso dos pais e mestres, traduzido e adaptado por Rui Barbosa, em 1886, o qual se tornou o manual para professores mais difundido e usado no Brasil durante os anos finais do Império e grande parte da Primeira República (Bastos, 2000). A obra analisada 


\section{pro.posıções}

$e$-ISSN 1980-6248

http://dx.doi.org/10.1590/1980-6248-2016-0070

refere-se à quadragésima edição de Primary Object Lessons, for training the senses and developing the faculties of children. A manual of elementary instruction forparents and teachers, escrita por Norman Allison Calkins $^{7}$ em 1884.

O manual organiza-se em lições específicas de diferentes saberes para o curso primário, e entre eles está o desenho. É importante destacar que não há lições de geometria no livro e sim lições de formas, nas quais são estudadas as figuras geométricas. As lições de desenho são reduzidas; segundo o autor, não há a intenção de desenvolver uma série de lições de desenho, mas simplesmente sugerir aos mestres os primeiros passos introdutórios, como traçar linhas vertical e horizontal, com extensão determinada.

Verifica-se que as lições de desenhos são muito próximas das lições de formas, visto que as figuras a serem desenhadas são todas geométricas, porém o ensino dos traçados articula-se com o da medida visual. As linhas e os ângulos são desenhados sem instrumentos geométricos, usa-se somente o lápis. O aluno deve exercitar a avaliação de medidas de linhas e ângulos através do olhar, e somente depois é feita a verificação com os instrumentos: "Educai as crianças em traçar, verificando-lhe depois o comprimento, linhas de extensão determinadas: de uma, duas, três, quatro polegadas, até que os discípulos se habituem a avaliar a ôlho ... Não comeceis por medir, nem vos guieis pela régua" (Barbosa, 1950, p. 362). Trata-se de desenho de figuras geométricas à mão livre.

Barbosa (1950) destaca que Calkins considera fundamental iniciar o estudo de desenho na escola primária pelo desenho à mão livre:

Depois de percorrer os passos que se acabam de esboçar, os alunos terão adquirido assaz habilidade manual no uso do lapis e segurança de olho no discernir as figuras e objetos, bem como no medir as extensões, para encetar com proveito um extenso curso de lições de desenho (p. 365).

A terceira obra estrangeira traduzida e adaptada para o português no século XIX reafirma a necessidade de iniciar o ensino de desenho pelas figuras geométricas planas, à mão livre. Entretanto, os três manuais sugerem atividades em que o desenho perfeito, com medidas precisas, é exigido pelo monitor ou professor, através do uso dos instrumentos para corrigir e

\footnotetext{
${ }^{7}$ Norman Allison Calkins foi mestre primário e diretor de escola, no interior do estado de Nova York. Transferiuse para essa cidade, em 1846, para dedicar-se à propaganda da renovação do ensino.
} 


\section{pro.posıções}

$e$-ISSN 1980-6248

http://dx.doi.org/10.1590/1980-6248-2016-0070

conferir a figura. Espera-se desenvolver habilidades nas mãos, com traçados firmes; e nos olhos, na precisão de medida por estimativa, ou seja, educar as mãos e os olhos.

Identificam-se princípios do método intuitivo pestalozziano nas três obras, como a "primazia da prática sobre a teoria" e "a intuição sensível como fundamento absoluto de todo conhecimento", na medida em que as atividades de desenhar se configuram como ações práticas, pautadas na observação, a serem executadas pelos alunos, sem necessidade de aportes teóricos e explicações sobre as figuras geométricas que são reproduzidas. Nesse sentido ainda, não se definem os saberes geométricos em questão - a prática de observar e reproduzir os desenhos é suficiente para fazer compreender as formas geométricas. No livro de Albuquerque, há de se assinalar a total liberdade dos alunos na execução dos desenhos; já na obra de Portella, o monitor executa a figura ao final. De todo modo, vale destacar a relevância da observação e das sucessivas reproduções de figuras geométricas como atividades iniciais para o processo de escolarização de saberes geométricos, traduzido por desenhar à mão livre as formas geométricas o mais perfeitamente possível. A propósito, segundo Pestalozzi (1801):

Esses elementos (as "formas", as coisas, as "relações numéricas", as "palavras") são essenciais porque elas correspondem a nossa verdadeira natureza de ser sensível, racional e falante: esses são os verdadeiros "elementos" [ênfase no original]. De fato, nosso conhecimento das coisas se opera naturalmente pelo reconhecimento das formas, o cálculo das medidas e sua tradução por palavras. (citado em Trouvé, 2008, p. 252, tradução nossa)

Em síntese, as obras traduzidas e adaptadas do estrangeiro permitem fazer circular as tendências modernizadoras do ensino, vindas da França, como dos EUA. Como já dito, o exame de tais propostas para a história da educação matemática revela elementos para a compreensão do processo de escolarização de saberes geométricos no Brasil.

\section{Práticas de desenho e saberes geométricos nos manuais brasileiros}

A primeira produção brasileira analisada, "Desenho linear on geometria prática popular", foi escrita por Abílio César Borges, o Barão de Macahubas, e publicada em 1876:

A primeira [viagem de Borges à Europa] ocorreu em 1866. De lá trouxe material pedagógico, professores, além de ter aproveitado para redigir alguns compêndios: "estou aproveitando a demora forçada, na composição segundo o que me tem ensinado a prática, e o que por cá tenho 


\section{pro.posıções}

$e$-ISSN 1980-6248

http://dx.doi.org/10.1590/1980-6248-2016-0070

visto, de algumas obrinhas elementares para as escolas brasileiras" (Alves, 1942, p.104). A segunda viagem deu-se em 1870, para tratamento de saúde, quando aproveitou para redigir outros textos e imprimir novos livros. (Saviani, 2010, pp. 142-143)

Apesar de ser considerado um autodidata em matéria de educação, Abílio Borges mantinha contato com o estrangeiro e produziu diversas obras para uso nas escolas - de leitura, gramática, entre outras. De acordo com Isaías Alves, cerca de 400 mil volumes das suas obras didáticas se distribuíram gratuitamente pelas províncias brasileiras (Saviani, 2010).

A versão analisada refere-se à oitava edição da obra e não contém data. $\mathrm{Na}$ capa indicase "Obra approvada para as escolas primarias do Distrito Federal e de varios estados". Há uma longa introdução escrita na segunda edição da obra, publicada em 1878, em que o autor faz sua defesa do ensino do desenho, cuja importância é destacada tanto para o desenvolvimento das faculdades humanas quanto para o progresso industrial, sendo considerado a linguagem de todo mundo:

O desenho, dizia Pestalozzi, é um auxiliar muito util para se ensinar a escripta; elle será para os mestres um meio excellente de tornar suas lições mais claras, e compensará largamente, facilitando o estudo das outras materias, o tempo que se lhe tiver consagrado. (Borges, 1878, p. XIII)

É ainda no prefácio da segunda edição que Borges (1878) tece críticas à proposta de ensino do desenho realizado como simples reprodução de modelos, prática essa sugerida nos manuais estrangeiros traduzidos e adaptados:

Para se chegar a este resultado é indispensavel proscrever de uma maneira absoluta a copia machinal de modelos [ênfase adicionada]como se pratica actualmente, e substituil-a por uma copia intelligente, que leva pouco a pouco o discipulo a exprimir suas proprias idéas. (p. XI)

O autor deixa clara a sua posição em relação ao ensino de desenho: "Um systema de desenho, ainda quando não tem por fim sinão o resultado artístico, deve tomar a geometria por guia desde o princípio até o fim” (citado por Borges, 1878, p. XV).

O manual não explica como é feita a construção dos desenhos, que fica a cargo do professor, porém apresenta as definições e as propriedades das figuras a serem desenhadas, juntamente com a representação gráfica ao lado, que ilustra os conceitos geométricos estudados. Ao final de cada capítulo, há sempre um questionário em que se pedem as definições e as 


\section{pro.posıções}

$e$-ISSN 1980-6248

http://dx.doi.org/10.1590/1980-6248-2016-0070

propriedades apresentadas anteriormente e um quadro sinóptico, o qual sintetiza e organiza as definições e as propriedades.

Apesar de Borges citar Pestalozzi, ao afirmar que o desenho é um auxiliar para a escrita e um meio de tornar as lições mais claras, a proposta do livro nega um dos princípios do educador suíço. De acordo com Trouvé (2008), Pestalozzi inverte totalmente o método habitual de instrução, que inicia a aprendizagem pelo ensino das definições de palavras: para ele, as palavras são somente introduzidas quando a criança esgota toda a arte de observação e de descrição das coisas: "Descrever antes de definir e bem ver (que significa observar) antes de descrever: isto parece ser o grande princípio pedagógico que comanda o método elementar" (p. 258, tradução nossa).

Os nomes e as definições de figuras geométricas caracterizam o livro de Borges, constituem o ponto de partida do ensino, visto que os desenhos ficam sob a responsabilidade do professor. Os questionários ao final de cada capítulo, como exercícios a serem executados pelos alunos, reiteram a importância de reproduzir a parte conceitual e formal, em detrimento da observação da forma e da reprodução à mão livre.

Não há orientação explícita sobre o uso de instrumentos; entretanto, nas primeiras páginas, o autor apresenta a lista de instrumentos empregados no desenho linear, ou seja, as práticas de desenho propostas devem fazer uso de tais instrumentos. Borges sugere a construção dos desenhos pelo professor no quadro-negro, explicando ao grupo de alunos, chamando a atenção para os pontos interessantes, excitando a curiosidade e provocando emulação pelas interrogações a um e a outro aluno (Borges, 1878, p. XI).

A segunda obra produzida por brasileiro foi publicada no Rio de Janeiro, em 1881, Curso elementar de desenho linear, de Paulino Martins Pacheco, e traz na capa a rubrica de "obra approvada pelo Conselho Director da Instrucção Pública e adoptada nas Escolas públicas primarias, secundarias e normais". Nas preliminares do manual, o autor esclarece a divisão do desenho linear em "linear à vista" e "linear gráfico":

Ainda que executado sem o auxílio de instrumentos, tem o primeiro [linear à vista] a vantagem de educar a vista e tornar a mão destra [ênfase adicionada] e firme para os trabalhos do segundo [linear gráfico]. Baseado na Geometria, sobre cujos principios assenta o desenho em geral, não pode o Linear à vista deixar de ser estudado como preparatório a qualquer dos ramos daquelle. (Pacheco, 1881, p. 12) 


\section{pro.posıções}

$e$-ISSN 1980-6248

http://dx.doi.org/10.1590/1980-6248-2016-0070

No prefácio, Pacheco indica que a primeira parte da obra, destinada às escolas primárias e ao primeiro ano da disciplina de Desenho, trata do linear à vista, isto é, das definições da Geometria plana e no espaço com as respectivas figuras, em cujo traçado convém que os alunos empreguem o maior cuidado possível, a fim de que se vão logo habituando à precisão dos trabalhos da parte seguinte (Pacheco, 1881). O traçado com régua e compasso inicia na segunda parte (não mais destinada ao primário), denominada "desenho linear gráfico".

Pode-se caracterizar a proposta do livro de Pacheco como uma posição intermediária, na medida em que defende a importância dos traçados à mão livre como introdutórios (educar a vista e tornar a mão destra) e preparatórios para o desenho com instrumentos, porém apresenta desde o início as definições das figuras geométricas.

Finalmente, a terceira e última obra analisada é o livro Primeiras noções de geometria prática, de Olavo Freire, publicado em 1894. A edição examinada neste artigo é a de número 8 e não tem data. A obra recebeu elogios de distintos jornais do País pela clareza da sua exposição e pela excelência do método adotado, que dá ao ensino de geometria a facilidade que os alunos não encontram em outros livros.

No prefácio, escrito em 1894, Menezes Vieira aponta que o livro se liberta dos velhos moldes e métodos e, em seguida, critica o caráter abstrato da obra: "Sinto, entretanto, que tivesses em um ponto transigido a rotina, preferindo problemas abstratos às questões práticas, cuja resolução se oferece todos os dias na vida social" (Vieira, 1894 citado por Freire, 1894, p. 7). Em nota de rodapé, Olavo Freire (1894) responde ao colega: "Não transigi em absoluto porque pretendo publicar uma série de problemas de caráter essencialmente prático” (p.7).

Trata-se de uma obra de saberes geométricos, com definições, exemplos, problemas e exercícios. No que diz respeito aos desenhos, Freire enfatiza as construções de figuras geométricas com instrumentos. Os 92 problemas resolvidos anunciados na capa do livro da oitava edição correspondem à sequência de construções geométricas com instrumentos: régua, compasso e esquadro.

De modo geral, as figuras geométricas são primeiramente definidas, destacando as propriedades características; em seguida, o autor apresenta uma sinopse, organizando definições e propriedades, de forma muito similar ao quadro sinóptico do livro de Borges. Observa-se como exemplo o quadrado: 


\section{pro.posições}

$e$-ISSN 1980-6248

http://dx.doi.org/10.1590/1980-6248-2016-0070

si um quadrilatero tem os lados iguaes, parallelos dois a dois e os ângulos rectos, toma o nome de quadrado. (Freire, 1894, p. 62);

Synopse: Quadrado - lados (iguaes e parallelos dois a dois), angulos retos, diagonaes (iguaes, perpendiculares entre si, dividem-se ao meio) (Freire, 1894, p. 63)

Após a definição das figuras, é apresentada a construção geométrica, com todos os passos que o aluno deve efetuar para obter a figura final, utilizando os instrumentos geométricos, em especial, régua e compasso. No exemplo do quadrado:

Problema XX. - Construir um quadrado, conhecendo-se um lado.

1a. Solução. - Sobre uma recta apliquemos o lado AM (conhecido) e de cada um dos pontos A e M levantemos, com o auxilio de um esquadro, uma perpendicular. Façamos as distancias AD e $\mathrm{MC}$ iguaes cada uma a $\mathrm{AM}$; unamos o ponto $\mathrm{D}$ ao ponto $\mathrm{C}$ e teremos construido o quadrado. (Freire, 1894, p. 67)

A inserção dos desenhos geométricos de figuras com emprego de régua, esquadro e compasso modifica o processo de escolarização dos saberes geométricos: a definição e as propriedades das figuras constituem os primeiros contatos com o conceito, o ponto de partida no processo de ensino; e o desenho construído assume o papel de uma representação da figura definida; a observação das formas das figuras e sua reprodução através do desenho à mão livre desaparecem. Todos os passos são apresentados prontos, para que o aluno os reproduza. A prática de desenhar é traduzida pelo uso adequado dos instrumentos e da sequência proposta pelo autor. Educar a mão com traços firmes é entendido como usar bem a régua, e educar a vista significa empregar adequadamente o esquadro e o compasso, de modo a obter medidas iguais de lados e ângulos.

O manual de Freire assume posição clara pelo desenho geométrico, em contraposição ao desenho à mão livre: nenhuma menção é feita no sentido de iniciar com traçados livres antes do emprego de instrumentos. É uma proposta de ensino de escolarização de saberes geométricos marcada pela formalização de definições, pelo uso precoce de instrumentos geométricos e pela memorização dos passos para a construção das figuras. A observação de propriedades, o treino de medidas por estimativa e o ensino ativo do aluno, no sentido de descobrir propriedades a serem reproduzidas, cedem lugar ao conceito pronto para ser decorado. 


\section{pro.posıções}

$e$-ISSN 1980-6248

http://dx.doi.org/10.1590/1980-6248-2016-0070

Os saberes geométricos sustentam a prática do desenho com instrumentos, a definição da figura geométrica é que justifica ou explica os passos empregados pelos instrumentos. A inserção do desenho geométrico como um conjunto de práticas iniciais de escolarização de saberes geométricos altera a relação entre os saberes em jogo - desenho e geométricos -, os aspectos formais e conceituais da geometria prevalecem, em detrimento de uma exploração e uma observação de maneira livre, em que o aluno é chamado a agir pela intuição e desenvolver habilidades básicas, não somente para o ensino de saberes geométricos, mas para a formação geral, como o educar as mãos e os olhos.

\section{Considerações finais}

Os manuais escolares analisados indicam a presença de duas propostas para o ensino de desenho e de saberes geométricos: o desenho à mão livre e o desenho geométrico, com instrumentos. O desenho à mão livre realizado pela cópia de figuras traz em sua prática a necessidade de observar e identificar propriedades que caracterizam as figuras geométricas - em outras palavras, vincula-se ao estudo das formas geométricas através do método intuitivo. De outra parte, o desenho geométrico, ao ser inserido nos manuais, apresenta-se associado às definições das figuras geométricas e com passos determinados para a construção.

O pesquisador D'Enfert (2007) comenta que o método de desenho à mão livre proposto pelo matemático Francœur no manual de 1819 torna-se modelo para vários outros autores de manuais na França. Entretanto, o manual passou por revisão em 1827 e em 1832, e a edição esboçou uma via intermediária: primeiro o desenho à mão livre e, em seguida, repete-se o desenho, empregando a régua e o compasso, similar à adaptação proposta por Portella, em que as mesmas figuras são desenhadas duas vezes: primeiro à mão livre e depois com instrumentos. No entanto, D’Enfert (2007) adverte que a abordagem de Francœur não representa unanimidade na França, pois há autores que publicam manuais excluindo totalmente o desenho à mão livre em favor dos traçados geométricos com régua e compasso e abrem o debate sobre a pertinência do desenho à mão livre:

Para os alunos mais jovens da escola elementar, o desenho à mão livre ensinado sem teoria explícita é privilegiado, a fim de exercer os sentidos e de se iniciá-los na geometria, para os alunos mais velhos, das escolas primárias superiores ou dos cursos de adultos, a ênfase é 


\section{pro.posições \\ $e$-ISSN 1980-6248}

http://dx.doi.org/10.1590/1980-6248-2016-0070

colocada no desenho linear "exato" [ênfase no original] e no uso dos instrumentos, às vezes, paralelamente ao curso de geometria. ( p. 58)

No Brasil, identificam-se dois manuais no período, que podem ser considerados como uma posição intermediária, conjugando práticas de desenho à mão livre e desenho geométrico. O manual de Portella, que insere a divisão de desenho com a mão levantada e desenho geométrico, e o manual de Pacheco, que se posiciona claramente como sendo necessário iniciar o ensino do desenho com figuras à mão livre. Contudo, tais manuais não fizeram escola, pois não foram identificadas edições posteriores.

De outra parte, os manuais de Borges e Freire, ambos caracterizados pelo desenho geométrico, com a presença das definições antecedendo as construções, seguiram até meados do século XX, com inúmeras edições, sempre revisadas e ampliadas.

O manual inovador de Freire, primeiro a apresentar grande quantidade de problemas de construções geométricas com todos os passos, seria a referência para o ensino de saberes geométricos no período de ampliação do modelo dos grupos escolares. Apesar de as traduções de manuais estrangeiros propagarem marcas do método intuitivo, em que o desenho à mão livre escolariza os saberes geométricos, tal proposta não prevaleceu nas produções brasileiras, que se caracterizaram pelo desenho geométrico de figuras previamente definidas, de modo que os saberes geométricos sustentavam a prática do desenho.

Com relação ao ensino de desenho, as críticas que circulavam no início do século XX, em particular nas revistas pedagógicas de São Paulo, incidiram não somente sobre o uso de instrumentos geométricos, mas igualmente sobre o objeto a ser desenhado, as formas geométricas; um novo método designado por “desenho ao natural” adentrou o debate educacional em defesa do desenho à mão livre de objetos da natureza, mas esta é outra história. 


\section{pro.posıções}

$e$-ISSN 1980-6248

http://dx.doi.org/10.1590/1980-6248-2016-0070

\section{Referências}

Albuquerque, A. F. de P. H. C. (1829). Princípios do desenho linear compreendendo os de geometria prática pelo método do ensino mútuo. Extraídos de L. B. Francoeur. Rio de Janeiro: Na Imperial Typographia de P. Plancher-Seignot.

Barbosa, R. (1950). Primeiras lições de coisas. Rio de Janeiro: Ministério da Educação e Saúde. In N. A. Calkins (1886), Obras completas de Rui Barbosa (Vol. XIII, tomo I).

Bastos, M. H. C. (1997, abril). A instrução pública e o ensino mútuo no Brasil: uma história pouco conhecida (1808-1827). História da Educaşão, (1), 115-133.

Bastos, M. H. C. (2000, setembro). Ferdinand Buisson no Brasil - Pistas, vestígios e sinais de suas idéias pedagógicas (1870-1900). História da Educação, (8), 79-109.

Borges, A. C. (n.d.). Desenho linear ou elementos de geometria pratica popular (8a ed.). Rio de Janeiro.

Chartier, R. (2009). A bistória on a leitura do tempo (C. Antunes, Trad.). Belo Horizonte: Autêntica.

Choppin, A. (2009, janeiro/abril). O manual escolar: uma falsa evidência histórica de (M. H. C. Bastos, Trad.). História da Educação, 13(27), 09-75.

D’Enfert, R. (2007, maio). Uma nova forma de ensino de desenho na França no início do século XIX: o desenho linear (M. H. C. Bastos, Trad.). Revista História da Educação, 22, 31-59.

D’Esquivel, M. O. (2015). O ensino de desenho e geometria para a escola primária na Babia (1835-1925).

Dissertação de Mestrado, Universidade Estadual do Sudoeste da Bahia, Jequié, Bahia.

Francœur, L.-B. (1819). Le dessin lineaire d'apres la methode de l'enseignement mutuel. Paris: L. Colas, Imprimeur - Libraire de la Société. Retirado em 14 de maio de 2016, de $<$ https://books.google.fr/books?id=FSFSAAAAcAAJ\&printsec $=$ frontcover\&hl=fr\& source $=$ gbs_ge_summary_r\&cad $=0 \# \mathrm{v}=$ onepage $\& \mathrm{q} \& \mathrm{f}=$ false $>$.

Freire, O. (n.d.). Primeiras noções de geometria pratica (8a ed.). Rio de Janeiro: Francisco Alves \& Cia. Matasci, D. (2015). L'école républicaine et l'étranger. Une historie internacionale des réformes scolaires en France 1870-1914. Lyon: Ens Editions.

Pacheco, P. M. (1881). Curso elementar de desenho linear. Rio de Janeiro: Imprensa Industrial. 


\section{pro.posıções \\ $e$-ISSN 1980-6248}

http://dx.doi.org/10.1590/1980-6248-2016-0070

Portella, J. A. (1854). Manual das escolas elementares d'ensino mútuo. Bahia: Typografia de A. O. da França Guerra e Comp.

Sarazin, M. (1831). Manuel des écoles élementaires. Paris: Louis Colas.

Saviani, D. (2010). História das ideias pedagógicas no Brasil (3a ed.). Campinas: Autores Associados.

Trouvé, A. (2008). La notion de savoir élémentaire à l'école. Paris: L'Harmattan.

Zanatta, B. A. (2012, janeiro/abril). O legado de Pestalozzi, Herbert e Dewey para as práticas pedagógicas escolares. Teoria e Prática da Educação, 15(1), 105-112.

Submetido à avaliação em 06 de junho de 2016; aceito para publicação em 15 de maio de 2017. 